\title{
Design and Build WEB-Based Applications as E-Commerce Media for Sales of Custom Products at CLOVE STORE Stores
}

\section{Rancang Bangun Aplikasi Berbasis WEB Sebagai Media E-Commerce Untuk Penjualan Produk Custom Pada Toko CLOVE STORE}

\author{
Nurul Hidayah, Mohammad Suryawinata, Hindarto, Ika Ratna Indra Astutik \\ \{161080200089@umsida.ac.id\}
}

Program Studi Sains dan Teknologi Informatika, Universitas Muhammadiyah Sidoarjo, Indonesia

\begin{abstract}
E-commerce provides information about the items offered by business actors in the form of catalogs, which are given to make it easier for the general public or potential purchasers to select the required product. Making this e-commerce application is for owners who have full control over the e-commerce website or administrators who can enter data on products or services offered, while visitors to e-commerce websites can place orders for those products or services. The results of testing a website-based e-commerce application on the Clove Store store from the trials that have been carried out show that the success rate is $90 \%$, In terms of the benefits of building an e-commerce website, there are many advantages, including for buyers, they don't need to come directly to the store, just by looking at the catalogs available on the website, buyers can directly order available products and for sellers in terms of promotion it will be easier and no need to spend more costs to market their products.
\end{abstract}

Keywords - Website; E-commerce

Abstrak. E-commerce memberikan informasi tentang produk yang di tawarkan oleh pelaku usaha beurpa katalog yang disajikan untuk mempermudah masyarakat atau calon pembeli dalam memilih produk yang di inginkan. Pembuatan aplikasi e-commerce ini di peruntukkan bagi owner yang memiliki hak penuh atas website e-commerce atau administator yang dapat memasukkan data produk atau jasa yang ditawarkan, sedangkan untuk pengunjung website e-commerce dapat melakukan pemesanan produk atau jasa yang di tawarkan. Hasil dari ujicoba aplikasi ecommerce berbasis website pada toko Clove Store dari uji coba yang telah dilakukan menunjukkan tingkat keberhasilan adalah 90\%, dari segi manfaat di bangunnya website e-commerce ini dapat banyak kelebihan diantaranya bagi pembeli tidak perlu datang langsung ke toko hanya dengan melihat katalog yang tersedia di website pembeli bisa langsung memesan produk yang tersedia dan untuk penjual dalam segi promosi akan lebih mudah dan tidak perlu mengeluarkan biaya lebih untuk memasarkan produknya.

Kata Kunci - Website; E-commerce

\section{Pendahuluan}

Seiring berjalannnya zaman perkembagan teknologi dan sistem informasi sudah sangat luar biasa, ini menjadi bukti bahwa peranannya berpengaruh penting pada suatu organisasi atau pelaku usaha, pemanfaatan sistem informasi dan teknologi informasi untuk membantu dalam mengembangkan dan memaksimalkan goal yang ingin dicapai [1], Salah satunya media internet digunakan sebagai media promosi dengan cara memanfaatkan internet yang terhubung ke sebuah website yang di dalamnya ada transaksi atau dapat juga disebut $e$-commerce.

E-commerce merupakan media transaksi menjual dan membeli dengan memanfaatkan jaringan internet untuk terhubung keberbagai media aplikasi yang menghubungkan antara penjual dan pembeli. survei ini dilakukan bersamaan dengan hari belanja online nasional oleh facebook yang hasilnya menunjukkan bahwa transaksi yang di lakukan dengan e-commerce terjadi peningkatan yang cukup berdampak pada perilaku transakasi yang dilakuakn di indonesia [2].

Toko Clove Store adalah usaha yang bergerak di bidang penjualan produk custom yang bermula penjualannya di lakukan melalui instagram dan facebook, karena factor persaingan antara banyak penjual yang bergerak di bidang yang sama yaitu custom dengan begitu toko clovestore memerlukan pembeda agar mendapatkan nilai lebih dan kepercayaan dari sisi konsumen maka dibuatlah media e-comerce untuk memenuhi target tersebut, dengan di buatnya media e-commerce tersebut juga akan ada banyak keuntungan yaitu efesiensi waktu, biaya dan mempermudah konsumen dalam melakukan transaksi.

\section{A. Internet}

Internet adalah suatu jaringan yang memungkinkan manusia dapat terhubung keseluru belahan dunia. Internet terhubung dari sebuah jaringan TCP/IP yaitu sebuah protokol yang menggunakan penomoran yang di sebut Internet 
Protocol Address (IP Address). Jika di lihat dari sejarahnya internet dan jaringan adalah dari hasil evolusi ARPANET proyek yang yang di usung oleh DARPA (Departemen Pertahanan Amerika Serikat), dalam resetnya tahun 1969 ARPANET membektuk satu jaringan terpadu dari 4 situs yang di hubungkan yaitu Standford Research Institute, Santa Barbara, University of California, University of Utah, kemudian diperkenalkan secara umum pada bulan Oktober 1972 oleh ARPANET [3].

\section{B. Web server}

Web server adalah server yang melayani permintaan clien sehingga memungkinkan dapat terhubung dengan Data Base, PHP, dan ASP, dengan cara menterjemahkan kode-kode tertentu. Dengan web server dapat menguji apakah aplikasi web sudah berjalan dengan baik atau belum sehingga tidak perlu melakukan mekanisme yang cukup mamakan waktu yang cukup lama seperti mengupload web server via internet untuk memeriksa kebenaran script yang telah di buat, dengan menggunakan web server lokal yang ter instal di dalam komputer adalah salah satu solusi yang sangat tepat [3].

\section{MySQL}

MySQL adalah salah satu dari aplikasi (DBMS) Data Base Management System yang di gunakan untuk mengelola basis data, dengan kemampuan keamanan yang cukup handal MySQL juga dapat berkomunikasi dengan aplikasi seperti PHP dan lainnya. Jika ingin banyak belajar atau banyak kendala ketika menggunakan MySQL sudah tersedia banyak forum yang mengkhususkan bahasan tentang MySQL sehingga memudahkan bagi user-user baru, dengan aplikasi DBSM yang handal software yang selalu diupdate dan juga gratis sehingga untuk memudahkan proses instalasi MySQL menjadi DBSM yang sering dibundling [3].

\section{XAMPP}

XAMPP berupa aplikasi dari web server yang memungkinkan clien dapat terhubung dengan file PHP, MySQL dan lain-lain tanpa harus terhubung dengan internet. XAMPP dan WAMP ini hampir mirip jika di lihat dari fitur yang disediakan, namun bedanya XAMPP dapat support bila di jalankan di beberapa Operating System Contoh Mac, Linux, Windows dan Solaris sehingga tidak akan masalah jika sering berpindah-pindah Operating System [3]

\section{E. Basis data}

Basis Data adalah himpunan atau kelompok berbagai data yang salaing terhubung antara satu dengan yang lainnya kemudian diorganisasikan agar data tersebut dapat mudah ditemukan ketika dibutuhkan sehingga proses pencarian data atau informasi tersebut dapat di proses dengan cepat dan mudah [3].

\section{F. Data flow diagram}

Data Flow Diagram adalah teknik gambaran jaringan sistem sebagai aliran data dengan fungsi-fungsi yang terhubung di aplikasikan dengan data yang bergerak dari input sampai output, atau dapat juga di artikan alat pembuat model yang di dalamnya menggambarkan sistem jaringan yang dihubungkan satu dengan yang lainnya menggunakan alur sitem data manual ataupun otomatis [4].

\section{G. Codeigniter}

CodeIgniter adalah framework yang membantu developer dalam membangun sebuah website tanpa harus mbuatnya dari awal karena framework ini dengan menggunakan metode MVC (Model, View, dan Controller) sehingga dapat memudahkan membangun sebuah website, framework ini bersifat open source [5].

\section{H. Boostrap}

Boostrap adalah framework aplikasi front-end yang memudahkan user untuk mengatur dan mengelolala tampilan dari website atau yang dapat dikatakan juga sebagai template paket lengkap untuk pemula hinnga yang sudah mahir. Untuk user yang hanya menguasai HTML dan CSS Bootstrap dapat sangat membantu user dalam membangun sebuah website karena Bootstrap dilengkapi dengan ftur yang kaya sehingga memper mudah dalam membangun sebuah website [6].

\section{E-commerce}

E-commerce atau Electronic commerce adalah aktifitas jual beli jasa, produk dan informasi yang dilakuakan dengan media internet, e-commerce dapat dilakukan melaui internet dengan media seperti Instagram dan Facebook atau juga bisa dari radio dan televisi. E-commerce dari perspektif bisnis dapat diartikan juga sebagai technology applications menuju otomatisasi transaksi bisnis dan work flow [7].

\section{J. Block chart}


Block Chart berfungsi memudahkan pengguna untuk memmahami alur sistem yang ada, Block Chart adalah pemodelan untuk proses, masukan, keluaran, dan transaksi dengan menggunakan simbol tetentu [8].

\section{METODE}

\section{A. Peracangan sistem}

Flowchart

Flowchart menjelaskan alat untuk langkah yang harus dilakukan untuk menyelesaikan masalah komputasi dalam bentuk simbol bagaimana alur sistem e-commerce akan berjalan [9].

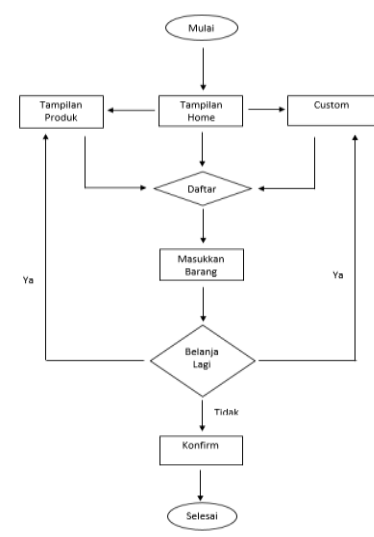

Gambar 1. Flowchart

Data Flow Diagram

Data Flow Diagram bertujuan untuk melihat aliran data dalam bentuk silbol yang terjadi perpindahan data dalam suatu proses sistem [10] website e-commerce yang akan dibangun.

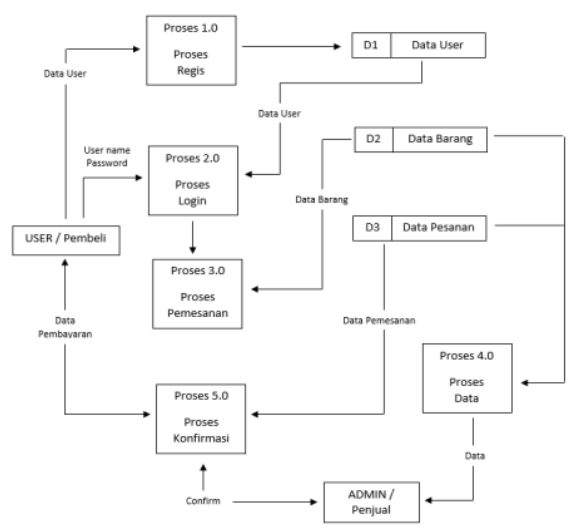

\section{B. Rancangan Desain Interface}

Gambar 2. Data Flow Diagram

Halaman utama

Pada gambar dibawah adalah menjelaskan antarmuka awal masuk website berisikan tombol-tombol menu yang memberikan informasi user untuk mendapatkan informasi yang ingin dilihat. 


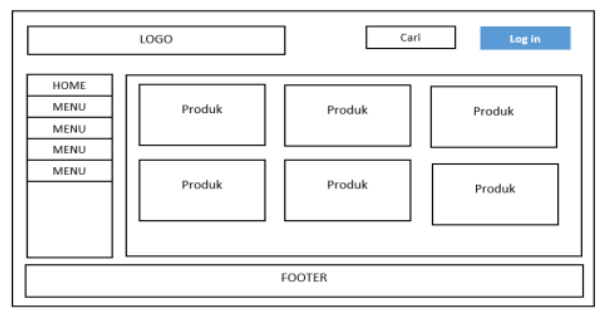

Gambar 3. Tampilan Halaman Utama

\section{Halaman login}

Gambar dibawah menjelaskan tampilan user untuk masuk ke tampilan utama agar dapat melakukan transaksi membeli produk

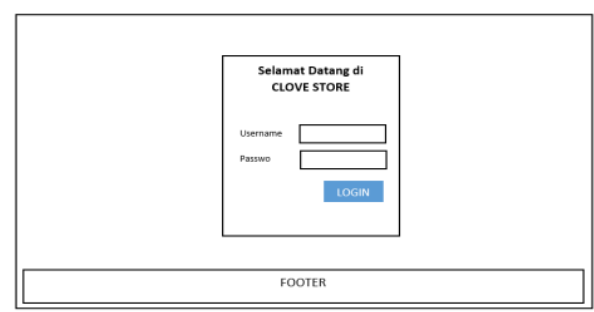

Gambar 4. Halaman Login

\section{Halaman admin}

Rancangan Gambar di bawah menjelaskan dimana tampilan untuk admin agar dapat melihat informasi pemesanan yang dilakukan konsumen.

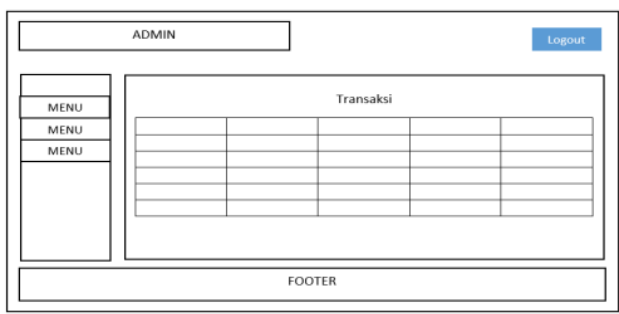

Gambar 5. Halaman Admin

\section{Rancangan Database}

Tabel user

Tabel ini berfungsi menyimpan data akun pendaftaran pembeli pada website yang akan di bangun nantinya

Tabel 1. Tabel User

\begin{tabular}{cccc}
\hline $\begin{array}{c}\text { Nama } \\
\text { Field }\end{array}$ & $\begin{array}{c}\text { Tipe } \\
\text { Data }\end{array}$ & $\begin{array}{c}\text { Ukuran } \\
\text { Field }\end{array}$ & Keterangan \\
\hline Id & Int & 11 & \\
Nama & Varchar & 50 & \\
Username & Varchar & 50 & \\
Password & Varchar & 50 & \\
Role_id & Tiny int & 1 & \\
\hline
\end{tabular}

Tabel barang

Tabel ini berfungsi untuk menyimpan data barang yang tersedia

Tabel 2. Tabel Barang 


\begin{tabular}{lccc}
\hline $\begin{array}{c}\text { Nama } \\
\text { Field }\end{array}$ & $\begin{array}{c}\text { Tipe } \\
\text { Data }\end{array}$ & $\begin{array}{c}\text { Ukuran } \\
\text { Field }\end{array}$ & Keterangan \\
\hline Id_brg & Int & 11 & \\
Nama_brg & Varchar & 120 & \\
Keterangan & Varchar & 225 & \\
Kategori & Varchar & 60 & \\
Harga & Int & 11 & \\
Stok & Int & 4 & \\
Gambar & Text & & \\
\hline
\end{tabular}

Tabel pesanan

Tabel ini berfungsi untuk menyimpan data pesanan barang yang di peasan oleh konsumen.

Tabel 3. Tabel Pesanan

\begin{tabular}{|c|c|c|c|}
\hline Nama & Tipe & Ukuran & Keteran \\
\hline Field & Data & Field & gan \\
\hline Id & Int & 11 & \\
\hline Id_invoic & Int & 11 & \\
\hline \multicolumn{4}{|l|}{ e } \\
\hline Id_brg & Int & 11 & \\
\hline Nama_br & Varcha & 50 & \\
\hline g & $\mathrm{r}$ & & \\
\hline jumlah & Int & 3 & \\
\hline Harga & Int & 10 & \\
\hline pilihan & Text & & \\
\hline
\end{tabular}

Tabel invoice

Tabel ini berfungsi untuk menyimpan data tagihan barang yang di beli konsumen.

Tabel 4. Tabel Invoice

\begin{tabular}{lccc}
\hline Nama Field & $\begin{array}{c}\text { Tipe } \\
\text { Data }\end{array}$ & $\begin{array}{c}\text { Ukuran } \\
\text { Field }\end{array}$ & Keterangan \\
\hline Id & Int & 11 & \\
Nama & Varchar & 56 & \\
Alamat & Varchar & 255 & \\
Tgl_pesan & Date & & \\
& time & & \\
Batas_bayar & Date \\
& time & \\
\hline
\end{tabular}

Tabel custom

Tabel ini berfungsi untuk menyimpan data pesanan produk custom

Tabel 5. Tabel Custom

\begin{tabular}{cccc}
\hline $\begin{array}{c}\text { Nama } \\
\text { Field }\end{array}$ & $\begin{array}{c}\text { Tipe } \\
\text { Data }\end{array}$ & $\begin{array}{c}\text { Ukuran } \\
\text { Field }\end{array}$ & Keterangan \\
\hline id_ctm & Int & 11 & \\
kategori & Varchar & 60 & \\
keterangan & Varchar & 225 & \\
Jumlah & Int & 5 & \\
Nama & Varchar & 60 & \\
alamat & Varchar & 225 & \\
no_telp & Varchar & 15 & \\
gambar & Text & & \\
\hline
\end{tabular}


Tabel riwayat

Tabel ini untuk menimpan data riwayat pemesanan

Tabel 6. Tabel Riwayat

\begin{tabular}{|c|c|c|c|}
\hline $\begin{array}{l}\text { Nama } \\
\text { Field }\end{array}$ & $\begin{array}{l}\text { Tipe } \\
\text { Data }\end{array}$ & $\begin{array}{l}\text { Ukuran } \\
\text { Field }\end{array}$ & $\begin{array}{l}\text { Keteran } \\
\text { gan }\end{array}$ \\
\hline id & Int & 11 & \\
\hline status & Varcha & 60 & \\
\hline & $\mathrm{r}$ & & \\
\hline tanggal & $\begin{array}{l}\text { Date } \\
\text { time }\end{array}$ & & \\
\hline nama & Varcha & 60 & \\
\hline & $\mathrm{r}$ & & \\
\hline nama_br & Varcha & 60 & \\
\hline g & $\mathrm{r}$ & & \\
\hline jumlah & Int & 11 & \\
\hline
\end{tabular}

\section{Hasil dan Pembahasan}

\section{A. Hasil pengujian}

Dari hasil uji dan percobaan yang dilakuakan untuk mengetahui sistem yang di bangun dapat berjalan dengan lancar sesui dengan modul-modul yang sudah di terapkan pada sistem yang sudah dibuat pada website e-commerce tersebut.

Pengujian modul akun

Pengujian pada modul ini bertujuan untuk mencoba keberhasilan sistem dari modul pendaftaran dan login.

Tabel 7. Pengujian modul akun

\begin{tabular}{|c|c|c|}
\hline Pengujian & Detail & $\begin{array}{c}\text { Hasil } \\
\text { Pengujian }\end{array}$ \\
\hline \multirow[t]{2}{*}{$\begin{array}{l}\text { Pendaftaran } \\
\text { akun }\end{array}$} & $\begin{array}{l}\text { a. Menguji apakah dapat memvalidasi kelengkapan } \\
\text { data modul pendaftaran jika salah satu tidak terisi }\end{array}$ & Berhasil \\
\hline & $\begin{array}{l}\text { b. Menguji apakah dapat melakuakn penambahan } \\
\text { akun baru }\end{array}$ & Berhasil \\
\hline \multirow[t]{3}{*}{ Login } & $\begin{array}{l}\text { a. Menguji apakah dapat memvalidasi kesesuaian data } \\
\text { akun saat login }\end{array}$ & Berhasil \\
\hline & $\begin{array}{l}\text { b. Menguji sistem apakah dapat melakukan validasi } \\
\text { hak akses member }\end{array}$ & Berhasil \\
\hline & $\begin{array}{l}\text { c. Menguji sistem apakah dapat melakukan validasi } \\
\text { hak akses admin }\end{array}$ & Berhasil \\
\hline
\end{tabular}

Pengujian alur pemesanan

Pengujian pada tahap ini bertujuan untuk mencoba keberhasilan sistem dari modul pemesanan.

Tabel 8. Pengujian alur pemesanan

\begin{tabular}{|c|c|c|}
\hline Pengujian & Detail & Hasil Pengujuan \\
\hline \multirow[t]{3}{*}{$\begin{array}{l}\text { Pengujian } \\
\text { Pemesanan }\end{array}$} & $\begin{array}{l}\text { a. Menguji apakah dapat menampilkan detail produk } \\
\text { yang akan dibeli }\end{array}$ & Berhasil \\
\hline & $\begin{array}{l}\text { b. Menguji apakah dapat melakukan tambah dan } \\
\text { hapus }\end{array}$ & Berhasil \\
\hline & $\begin{array}{l}\text { c. Menguji apakah dapat memvalidasi kesesuaian } \\
\text { jumlah barang dan jumlah total yang akan di bayar } \\
\text { d. Menguji apabila keranjang belanja kosong }\end{array}$ & Berhasil \\
\hline $\begin{array}{l}\text { Input Form } \\
\text { Pembayaran }\end{array}$ & $\begin{array}{l}\text { a. Menguji apakah dapat memvalidasi kelengkapan } \\
\text { data modul pembayaran jika salah satu tidak terisi }\end{array}$ & $\begin{array}{l}\text { Berhasil } \\
\text { Tidak berhasil }\end{array}$ \\
\hline
\end{tabular}




\begin{tabular}{lccc}
\hline & b. & Menguji modul keberhasilan check out pemesanan & Berhasil \\
$\begin{array}{l}\text { Input Form } \\
\begin{array}{l}\text { Pemesanan } \\
\text { Custom }\end{array}\end{array}$ & a. $\quad \begin{array}{l}\text { Menguji apakah dapat memvalidasi kelengkapan } \\
\text { data modul pembayaran jika salah satu tidak terisi }\end{array}$ & Tidak Berhasil \\
& b. $\begin{array}{l}\text { Menguji modul keberhasilan pemesanan produk } \\
\text { custom }\end{array}$ & Berhasil \\
\hline
\end{tabular}

Pengujian modul admin

Pengujian pada modul ini bertujuan untuk melihat keberhasilan dari modul-modul yang ada di halaman admin.

Tabel 9. Pengujian Modul Admin

\begin{tabular}{|c|c|c|}
\hline Pengujian & Detail & Hasil Pengujian \\
\hline \multirow[t]{4}{*}{ Data Barang } & $\begin{array}{l}\text { a. Menguji apakah berhasil menampilakan data barang di } \\
\text { halaman admin dan halaman utama. }\end{array}$ & Berhasil \\
\hline & $\begin{array}{l}\text { b. Menguji apakah dapat melakukan perintah tambah, edit, } \\
\text { dan hapus data barang. }\end{array}$ & Berhasil \\
\hline & $\begin{array}{l}\text { c. Menguji apakah dapat memvalidasi kelengkapan data } \\
\text { modul form input barang jika salah satu tidak terisi. }\end{array}$ & Berhasil \\
\hline & $\begin{array}{l}\text { d. Menguji apakah pada saat ada pemesanan jumlah stok } \\
\text { barang akan berkurang. }\end{array}$ & Berhasil \\
\hline \multirow{2}{*}{$\begin{array}{l}\text { Data Pesanan } \\
\text { Produk Jadi }\end{array}$} & a. Menguji apakah data pemesanan yang dilakukan dapat & Berhasil \\
\hline & $\begin{array}{l}\text { b. Menguji apakah dapat membaca dan menampilkan } \\
\text { detail pemesanan sesuai yang dipesan. }\end{array}$ & Berhasil \\
\hline \multirow[t]{2}{*}{$\begin{array}{l}\text { Data Pesanan } \\
\text { Produk Custom }\end{array}$} & $\begin{array}{l}\text { a. Menguji apakah data pemesanan yang dilakukan dapat } \\
\text { tampil di menu pesanan custom. }\end{array}$ & Berhasil \\
\hline & $\begin{array}{l}\text { b. Menguji apakah dapat membaca dan menampilkan } \\
\text { detail gambar. }\end{array}$ & Berhasil \\
\hline
\end{tabular}

\section{B. Tampilan Interface}

Halaman utama member

Halaman utama ini adalah halaman utama yang hanya dapat di akses setelah pengunjung menjadi member

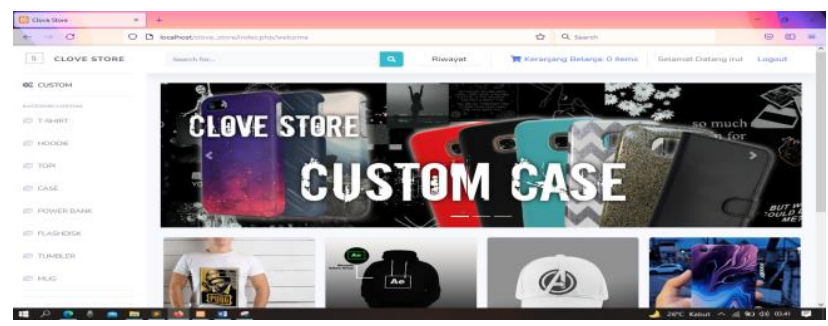

Gambar 6. Halaman Utama Member

\section{Halaman login}

Halaman ini di gunakan member dan admin yang akan ditujukan kehalaman masing-masing sesuai hak aksesnya.
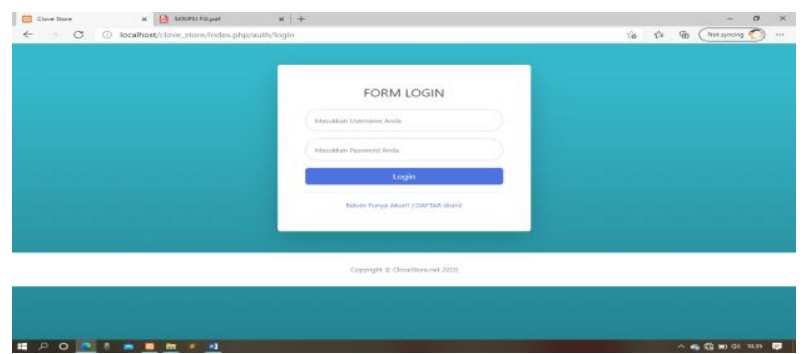

Gambar 7. Halaman login 


\section{Halaman admin}

Halaman admin adalah tempat dimana pengelola toko untuk mengelola data barang, stok barang, dan data pemesanan yang masuk di website toko clove store.

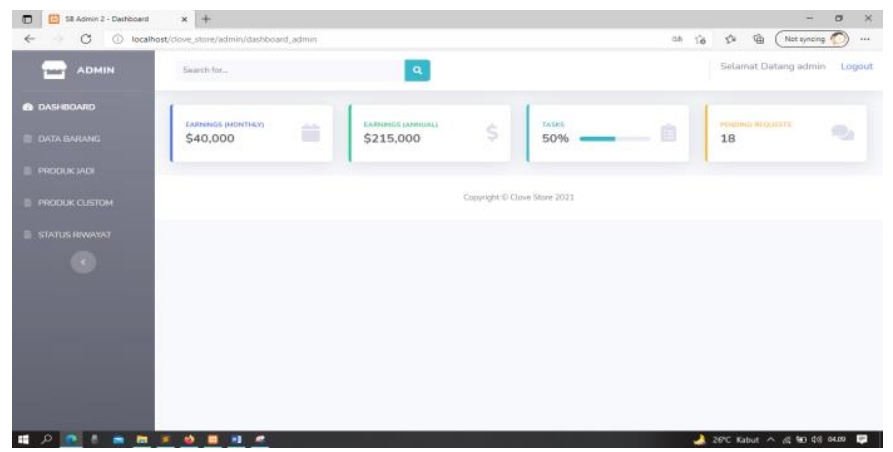

Gambar 8. Halaman admin

\section{KESIMPULAN}

Kesimpulan dari pembuatan aplikasi e-commerce toko Clove store ini adalah dilihat dari hasil uji coba yang telah dilakukan pada 20 modul percobaan di dapatkan 18 modul yang ber hasil dan 2 modul tidak berhasil, jadi persentase keberhasilan dari aplikasi e-commerce toko Clove Store yang telah di bangun tingkat keberhasilannya adalah $90 \%$. Serta manfaat yang di dapat dari aplikasi ini yang pertama dari sisi custemer lebih efisiensi waktu dan tenaga dari sisi owner dapat lebih leluasa dalam mempromosikan produk dan lebih hemat biaya.

\section{REFERENSI}

[1] H. A. Mumtahana, S. Nita, and A. W. Tito, "Pemanfaatan Web E-Commerce untuk meningkatkan strategi pemasaran,” Khazanah Inform. J. Ilmu Komput. dan Inform., vol. 3, no. 1, pp. 6-15, 2017.

[2] A. Sugara and R. Y. Dewantara, "Analisis Kepercayaan dan Kepuasan Terhadap Penggunaan Sistem Transaksi Jual Beli Online (Studi Pada Konsumen 'Z'),' J. Adm. Bisnis, vol. 52, no. 1, pp. 8-15, 2017.

[3] P. Hidayatullah, "Pemrograman Web Edisi Revisi," 2018.

[4] B. A. Herlambang and V. A. V. Setyawati, "Perancangan Data Flow Diagram Sistem Pakar Penentuan Kebutuhan Gizi Bagi Individu Normal Berbasis Web," J. Inform. UPGRIS, vol. 1, pp. 78-85, 2015.

[5] M. Destiningrum and Q. J. Adrian, "Sistem Informasi Penjadwalan Dokter Berbassis Web Dengan Menggunakan Framework Codeigniter (Studi Kasus: Rumah Sakit Yukum Medical Centre)," J. Teknoinfo, vol. 11, no. 2, p. 30, 2017, doi: 10.33365/jti.v11i2.24.

[6] A. Christian, S. Hesinto, and A. Agustina, "Rancang Bangun Website Sekolah Dengan Menggunakan Framework Bootstrap ( Studi Kasus SMP Negeri 6 Prabumulih )," J. Sisfokom (Sistem Inf. dan Komputer), vol. 7, no. 1, p. 22, 2018, doi: 10.32736/sisfokom.v7i1.278.

[7] L. Setiawan, "Pembuatan website e-commerce Butik diar lutfi Surakarta," 2009.

[8] A. Kristanto, "Perancangan Sistem Informasi dan Aplikasinya (Edisi Revisi)," Gava Media, 2018.

[9] R. Nuraini, "Desain algorithma operasi perkalian matriks menggunakan metode flowchart," J. Tek. Komput., vol. 1, no. 1, pp. 144-151, 2015.

[10] Y. Surono, "Data Flow Diagram (Dfd) pada Apotek Candra Kota Jambi," J. Ilm. Univ. Batanghari Jambi, vol. 14, no. 4, pp. 56-64, 2017. 